\title{
SENTRA KULAKAN MEDIA PEMBERDAYAAN UMKM
}

\author{
Agus Suprapto ${ }^{1)}$, Andi Poerwanto S. ${ }^{2)}$ \\ Fakultas Teknik, Universitas Merdeka Malang ${ }^{1)}$ \\ Fakultas Hukum, Universitas Merdeka Malang ${ }^{2)}$
}

\begin{abstract}
Abstrak
Sentra Kulakan merupakan penopang ekonomi bagi pelaku UMKM dan masyarakat kurang mampu. Adanya sentra kulakan yang menyediakan kebutuhan bahan baku bagi UMKM telah memberikan pengaruh besar atas berdirinya kembali UMKM yang mati suri. Banyaknya sentra kulakan yang berdiri di beberapa wilayah kabupaten Malang dan kota Malang menggairahkan kembali usaha kecil yang ada diwilayahnya. Selain akses pengadaan bahan baku dengan cara pembelian angsuran, beberapa pelatihan juga perlu dilakukan untuk memberikan penguatan kemampuan mereka dalam aspek produksi, aspek manajemen dan juga akses permodalan ke lembaga keuangan.
\end{abstract}

Kata Kunci : Sentra Kulakan, UMKM

\section{PENDAHULUAN}

Tidak bisa dipungkiri, perumbuhan ekonomi suatu daerah lebih banyak didominasi oleh kegiatan UMKM termasuk usaha sektor informal. Disepanjang jalan, di sekolah maupun di tempat keramaian/area publik, usaha sektor informal banyak bertebaran, dari sekian banyak sektor informal yang ada, kebanyakan bergerak dibidang penjualan makanan dan minuman. Jika usaha sektor informal ini bisa dikelola dengan baik tingkat kesejahteraan masyarakat akan baik, namun kenyataan dilapangan seringkali usaha sektor informal ini tidak bisa berjalan/bertahan apalagi mensejahterakan keluarga.

Permasalahan yang dihadapi para pelaku usaha sektor informal antara lain: 1) kekurangan modal usaha, dikarenakan modal usaha seringkali bercampur dengan kebutuhan keluarga artinya ketika memperoleh penghasilan dari usahanya, penghasilan ini tidak disimpan sebagai modal usaha berikutnya tetapi untuk menutup kebutuhan rumah tangga, sehingga seringkali hari berikutnya tidak bisa berusaha lagi karena kekurangan modal 2) sulit mendapatkan pinjaman karena tidak memiliki jaminan barang maupun kepercayaan dari keuangan sektor formal maupun sektor informal, sehingga untuk membiayai usahanya hanya bisa mengandalkan pinjaman saudara atau menjual barang berharga yang ada dirumah, 3) Kesulitan mendapatkan bahan sesuai dengan kebutuhan, dengan keterbatasan modal (uang) yang dimiliki menyebabkan usaha sektor informal tidak bisa berkembang karena jumlah bahan yang dibeli menjadi sangat terbatas, dan tentunya hal ini akan juga berpengaruh pada jumlah produk yang dihasilkan. 4) Manajemen usaha yang kurang baik dikarenakan masih tercampur antara kebutuhan usaha dengan kebutuhan rumah tangga.

Untuk itulah perlu adanya pemberdayaan bagi pelaku UMKM agar UMKM bisa hidup kembali. Dengan membentuk sentra kulakan di daerah diharapkan agar pelaku UMKM bisa mendapatkan kepastian pasokan bahan baku agar operasional mereka bisa dipertahankan. Dalam perkembangannya sentra kulakan mengalami pertumbuhan yang cukup pesat, hal ini bisa dilihat dengan semakin banyak terbentuk sentra kulakan didesa yang menjadi binaannya. Perkembangan sentra kulakan baik dalam jumlah maupun dalam kapasitas usaha dibarengi dengan semakin banyak UMKM binaan yang hidup kembali. UMKM yang selama ini mati suri mendapat angin segar dengan berdirinya sentra kulakan yang ada di wilayahnya. Dengan bantuan permodalan berupa barang dagangan yang bisa dibeli dengan harga murah dan dapat dibayar dengan cara diangsur memotivasi pelaku UMKM untuk bangkit kembali membangun usaha mereka, selain bantuan barang dagangan pelaku UMKM juga mendapat bantuan berupa peralatan produksi untuk mendukung operasional mereka.

Banyaknya UMKM yang gulung tikar dikarenakan manajemen yang kurang bagus serta keterbatasa permodalan menginspirasi tim untuk memperluas jangkauan sentra kulakan yang dibentuk. Pada tahun 2015 sentra kulakan yang dibentuk hanya sebatas wilayah Kec Karangploso dan Kec Lawang Kabupaten Malang, tahun 2016 ini jangkauan wilayah sudah berkembang ke Kec. Blimbing Kota Malang dan Kec Wonosari Kabupaten Malang. 


\section{METODE KEGIATAN}

\section{a. Kegiatan yang dilakukan}

1) Pelatihan Pembuatan Nugget Ayam dan Ikan Tuna

Pelatihan pembuatan nugget ayam dan ikan tuna dilaksanakan pada hari Jum'at tanggal 29 April 2016 di desa Ngijo Kec Karangploso. Pelatihan diikuti oleh 15 orang anggota dari sentra kulakan binaan Unmer. Kegiatan pelatihan ini dimaksudkan untuk meningkatkan ketrampilan ibu-ibu untuk bisa menghasilkan makanan untuk konsumsi keluarga yang sehat dan higienis, selain itu diharapkan setelah mengikuti pelatihan para ibu anggota sentra kulakan bisa lebih produktif untuk menghasilkan nugget untuk bisa dijual disentra kulakan sehingga bisa membantu menopang ekonomi keluarga.
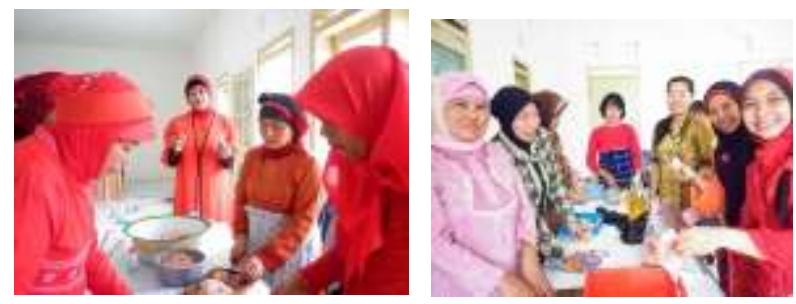

Gb 1. Pelatihan Pembuatan Nugget ayam dan ikan tuna

\section{2) Pengadaan Peralatan Produksi UMKM}

Meningkatnya permintaan atas produk UMKM binaan Sentra Kulakan Kaliarto Lawang mulai memunculkan beberapa permasalahan bagi UMKM tersebut karena peralatan produksi yang mereka miliki berkapasitas kecil, hal ini menyebabkan UMKM tidak bisa memenuhi permintaan pasar, sehingga keuntungan yang bisa mereka raih menjadi kecil. Untuk mengatasi hal tersebut, maka tim IbW memberikan bantuan beberapa peralatan kepada UMKM . Penyerahan bantuan dilakukan pada tanggal 12 Mei 2016 pukul 14.00
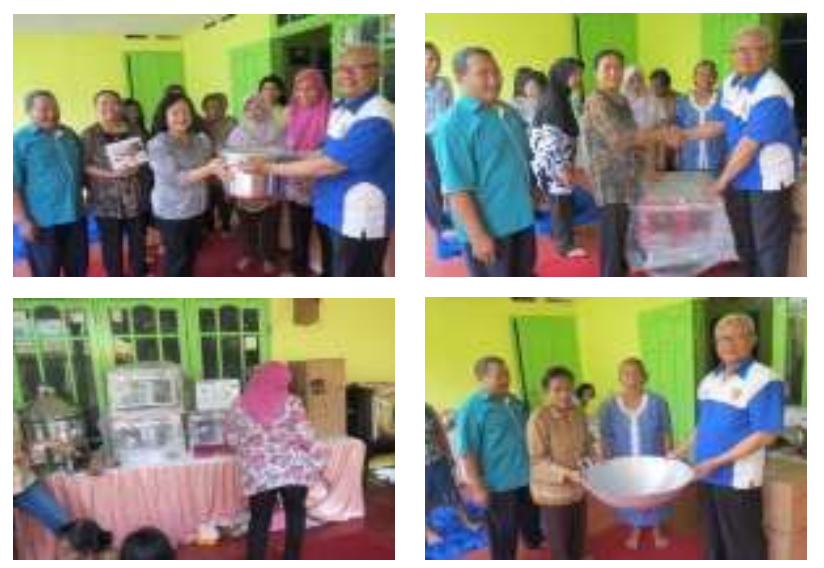

Gb 2. Penyerahan Peralatan Produksi kepadaUMKM

\section{3) Pelatihan Pembuatan Produk Kue Kering}

Pelatihan Pembuatan Kue Kering, diikuti oleh 20 orang ibu anggota sentra kulakan, dilaksanakan pada hari Selasa 17 Mei 2016, mulai pukul $15.00 \mathrm{~s} / \mathrm{d}$ selesai, bertempat di sentra kulakan Kaliartho Kec Lawang. Sebagian besar UMKM binaan sentra kulakan Kaliarto adalah pelaku usaha pembuatan kue kering, pelatihan ini dimaksudkan untuk memberikan ketrampilan kepada ibu-ibu anggota yang tidak memiliki usaha agar bisa menghasilkan produk kue kering untuk membantu UMKM yang ada dalam memenuhi permintaan pasar.
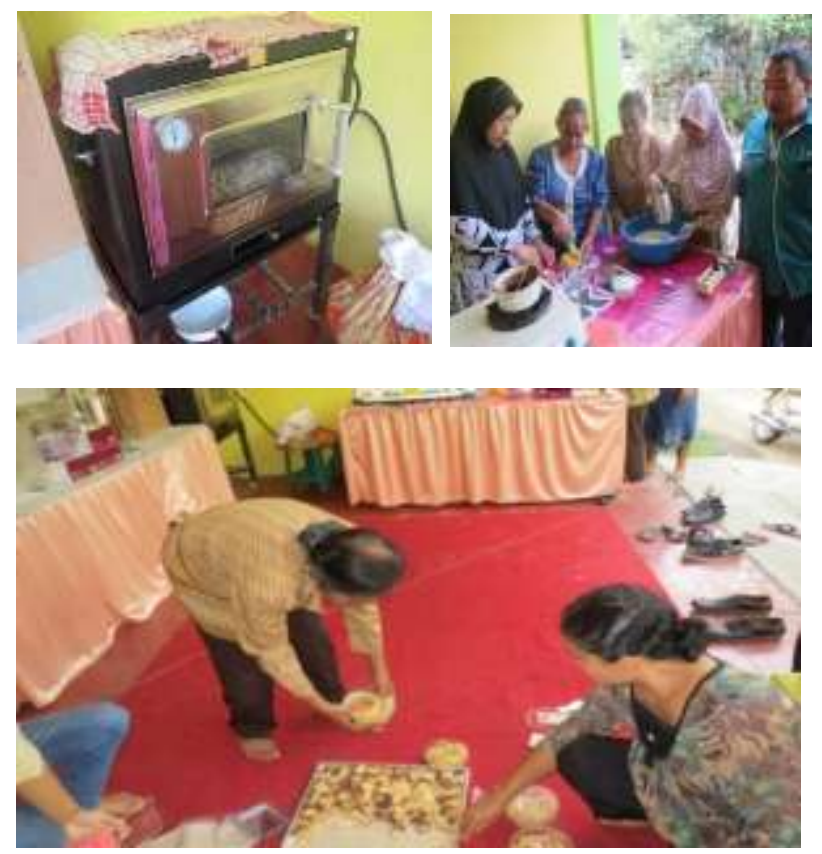

Gb 3. Pelatihan Pembuatan Kue Kering

4) Pengadaan Barang Dagangan

Dengan semakin banyak UMKM serta sentra kulakan yang dibentuk di beberapa wilayah menyebabkan sentra kulakan induk harus berusaha menyediakan kebutuhan mereka yang semakin meningkat, untuk itu maka perlu penguatan permodalan bagi Sentra Kulakan induk untuk menambah barang dagangannya, tambahan barang dagangan yang diberikan sangat membantu sentra kulakan Lumbung Artha Jaya, karena dana yang mereka miliki bisa digunakan untuk membeli kebutuhan lain yang juga sangat dibutuhkan masyarakat sekitar serta anggota lainnya. Penyerahan barang dilaku kan tanggal 24 Mei 2016 Pukul 13.00 

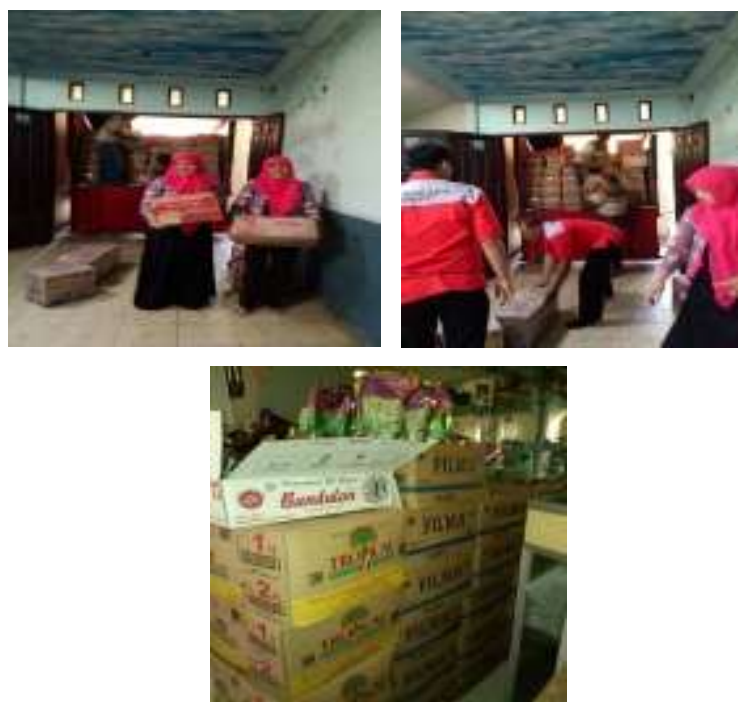

Gb 4. Bantuan barang dagangan di Sentra Kulakan Lumbung Artha Jaya

5) Pelatihan Penyusunan Business Plan

Adanya tawaran pendanaan dari lembaga keuangan dengan biaya murah bagi pelaku UMKM, menginspirasi untuk mengadakan pelatihan kepada pelaku UMKM membuat business plan, dengan business plan akan diketahui bagaimana cash flow usaha, bagaimana rencana pengembangan usaha serta, apakah usaha ini layak diberikan pinjaman ataukah tidak dengan mengetahui kapan dana yang dipinjamkan akan bisa dikembalikan oleh pelaku usaha. Pelatihan dilakukan di LPPM Unmer pada tanggal 10 juni 2016 Pukul 08.00-11.00 diikuti oleh 20 org Pelaku UMKM.


Gb 5. Pelatihan penyusunan busness plan

6) Pelatihan Pembukuan Sederhana

Hampir semua UMKM memiliki kelemahan dalam hal catat mencatat hasil usaha, semua kegiatan usaha baik keluar maupun masuknya uang jarang sekali yang tercatat secara rapi, sehingga jika ditanya bagaimana perkembangan usahanya mereka tidak bisa menjelaskan secara kuantitatif. Kelemahan ini menyebabkan UMKM jarang yang bisa mengakses pendanaan dari lembaga keuangan dengan jumlah relatif besar. Untuk itu perlu dilakukan pelatihan pembukuan sederhana bagi pelaku UMKM agar usahanya bisa terkontrol dan membuka peluang kepada UMKM untuk bisa melakukan akses ke lembaga keuangan formal untuk mendapatkan pinjaman dengan jumlah relatif besar sehingga usahanya bisa berkembang dengan lebih baik. Pelatihan dilakukan pada 17 Juli 2016 pukul $10.00-13.00$ diikuti 15 orang
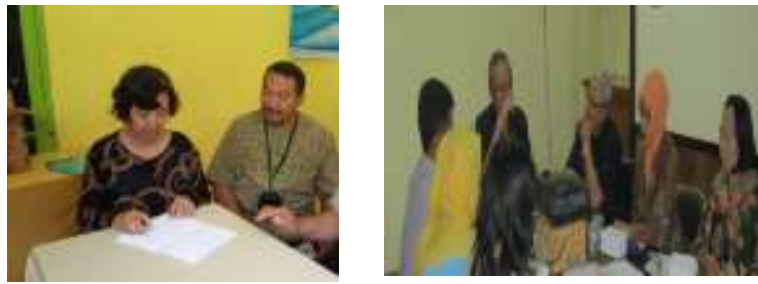

Gb 6. Pelatihan Pembukuan sederhana

7) Pelatihan Pembuatan Kerajinan Rajut

Pelatihan pembuatan kerajinan rajut diadakan, pada tanggal 21 Mei 2016 di Rumah Rajut binaan ibu Titin Kel Kedungkandang Kec Kedungkandang Malang

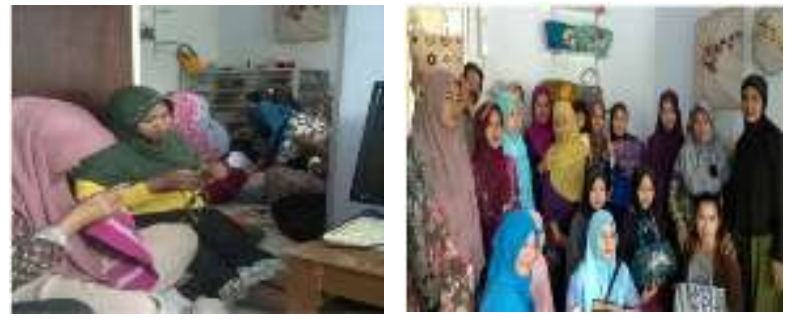

Gb 7.Pelatihan Pembuatan Kerajinan Rajut

8) Pelatihan lukis kain/Jilbab

Pelatihan lukis kain diadakan oleh Ibu PKK Kec Karangploso di Pendopo Kelurahan Ngijo Kec Karangploso Kab Malang, anggota dan pengurus sentra kulakan Lumbung Artha Jaya yang berkesempatan mengikuti acara ini.

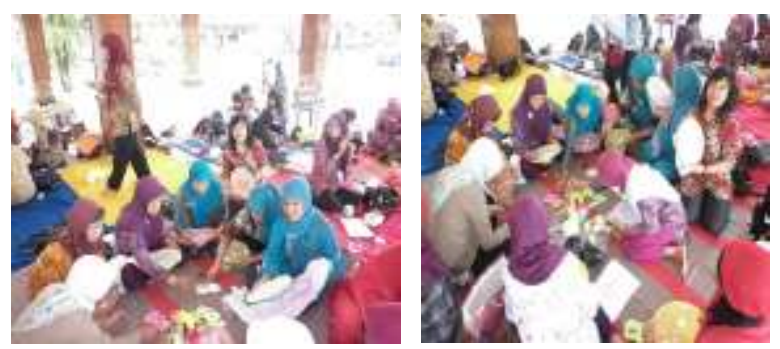

Gb 8.Pelatihan lukis kain (jilbab) 
9) Pelatihan Pembuatan rolade ayam sintetis

Pelatihan pembuatan rolade ayam sintetis berbahan tepung dan sayur segar diadakan untuk menggiatkan ekonomi keluarga prasejahtera. Pelatihan diikuti ibuibu anggota sentra kulakan

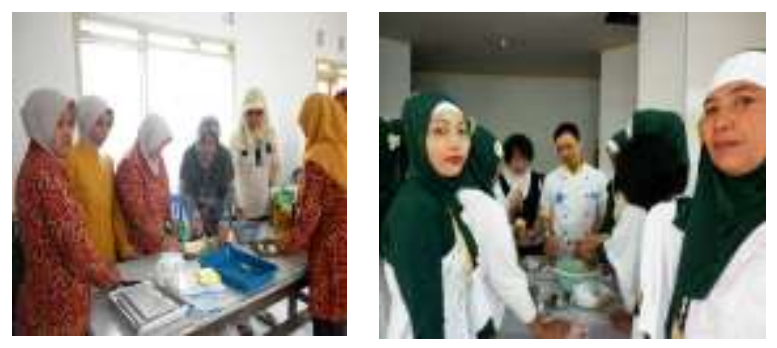

Gb 10. Pelatihan pembuatan Rolade

\section{HASIL DAN PEMBAHASAN}

Pada tahun 2016 telah terbentuk enam sentra kulakan dan 24 UMKM binaan, enam sentra kulakan yang dibentuk adalah : 1) Sentra kulakan yang dikelola ibu Hera di wilayah Kec Blimbing Kota Malang, 2) Sentra kulakan ibu Wiyanti Karangploso serta 3) Sentra kulakan yang dikelola Kopwan Kartika Kencana desa Kebobang Kec Wonosari Kab Malang, 4) Sentra Kulakan ibu Nganti Piwelas Kalirejo Lawanf, 5) Sentra Kulakan ibu Wiwin Kalirejo Lawang dan 6) Sentra Kulakan ibu Lilik Kalirejo Lawang . Dengan semakin luas wilayah binaan menunjukkan bahwa keberadaan sentra kulakan bagi UMKM ini sangat berarti dan bermanfaat. Dengan rasa saling mempercayai kerjasama tidak hanya dilakukan di wilayah kec Lawang dan Kec Karangploso saja tetapi juga kec Blimbing Kota Malang dan Kec Wonosari Kab Malang. Sementara tambahan UMKM yang menjadi binaan sentra kulakan sejumlah 25 UMKM.

Selain secara kelembagaan telah banyak terbentuk sentra binaan dan juga UMKM binaan, jika dilihat pertumbuhan asset, penjualan serta keuntungan , maka sentra kulakan induk serta binaan utama telah mengalami perkembangan yang pesat.

\section{a. Daftar sentra kulakan}

Sentra kulakan adalah pusat belanja terutama kebutuhan pokok dan bahan baku untuk pelaku UMKM maupun masyarakat kurang mampu dengan harga relatif murah, dengan metode pembayaran cicilan yang berdomisili di Kec Lawang, Kec Karangploso dan Kec Wonosari Kab Malang dan Kec Blimbing Kota Malang. Keberadaan sentra kulakan yang menyebar memudahkan pelaku
UMKM dan masyarakat kurang mampu untuk mengakses kebutuhan hidup dan kebutuhan usahanya.

\begin{tabular}{|l|l|l|}
\hline No & $\begin{array}{c}\text { Nama Pengelola } \\
\text { Sentra Kulakan }\end{array}$ & Lokasi Sentra Kulakan \\
\hline \multicolumn{2}{|l|}{ Tahun 2015} \\
\hline 1 & Erlin Sulistyowati & Ngijo Karangploso \\
\hline 2 & Anny Sulistyowati & Ketindan Lawang \\
\hline 3 & Dwi Martiana & Kalirejo Lawang \\
\hline 4 & Ponadi & Bedali Lawang \\
\hline 5 & Mulyati & Kendalsari Karangploso \\
\hline 6 & Supriani & Ngjjo Karangploso \\
\hline 7 & Indra Maria & Ngijo Karangploso \\
\hline 8 & Yayuk & Ngjjo Karangploso \\
\hline 9 & Ingsun Sayekti & Ngjjo Karangploso \\
\hline 10 & Halimah & Ngjjo Karangploso \\
\hline 11 & Komariah & Ngjjo Karangploso \\
\hline 12 & Kartini & Ngjjo Karangploso \\
\hline
\end{tabular}

\begin{tabular}{|l|l|l|}
\hline No & $\begin{array}{c}\text { Nama Pengelola Sentra } \\
\text { Kulakan }\end{array}$ & \multicolumn{1}{|c|}{ Lokasi Sentra Kulakan } \\
\hline \multicolumn{2}{|l|}{ Tahun 2016} & Kec Blimbing Kota Malang \\
\hline 1 & Hera & Ngijo Karangploso \\
\hline 2 & Wiyanti & Ds Kebobang Kec Wonosari \\
\hline 3 & Kopwan Kartika Kencana & Kalirejo Kec Lawang \\
\hline 4 & Wiwin & Kalirejo Kec Lawang \\
\hline 5 & Nganti Piwelas & Kalirejo Kec Lawang \\
\hline 6 & Lilik & \\
\hline
\end{tabular}

\section{b. Daftar UMKM}

UKMK merupakan binaan dari sentra kulakan yang ada di wilayah Kec Lawang dan Kec Karangploso Kab Malang, dimana para pelaku UMKM ini membeli bahan baku dari sentra kulakan dengan cara membayar angsuran, artinya mereka mengambila bahan baku ke sentra kulakan untuk produksi, kemudian akan membayar ketika barang dagangan mereka telah laku, terutama untuk UMKM yang mati suri, dengan harapan usaha mereka bisa dibangkitkan kembali. 


\begin{tabular}{|c|c|c|c|}
\hline No & $\begin{array}{l}\text { Nama Pelaku } \\
\text { UMKM }\end{array}$ & Jenis Usaha & Alamat \\
\hline \multicolumn{4}{|c|}{ Tahun 2015} \\
\hline 1 & Suharti & Onde-onde & Ngijo Karangploso \\
\hline 2 & Siti Sa'diah & Tepung bumbu & Ngijo Karangploso \\
\hline 3 & Umi Kulsum & Krupuk Bawang & Ngijo Karangploso \\
\hline 4 & Marem Rahayu & Bakpao & Ngijo Karangploso \\
\hline 5 & Wiyanti & Chesee Stick & Ngijo Karangploso \\
\hline 6 & Titin & Opak Gambir & Ngijo Karangploso \\
\hline 7 & Ema & Kue Basah & Ngijo Karangploso \\
\hline 8 & Ratna dkk (kel 1) & Kerajinan tangan & Kalirejo Lawang \\
\hline 9 & Sungkowo dkk (kel 2) & Minuman herbal & Kalirejo Lawang \\
\hline 10 & Sahnan dkk (kel 3) & Stick dan knipik & Kalirejo Lawang \\
\hline 11 & Warsini dkk (kel 4) & Kue kering & Kalirejo Lawang \\
\hline 12 & Cak Mun & Manisan herbal & Ketindan Lawang \\
\hline 13 & Catering $2 \mathrm{~A}$ & Kue kering, kue basah & Ketindan Lawang \\
\hline 14 & Indra & Catering makanan, kue & Ketindan Lawang \\
\hline \multicolumn{4}{|c|}{ Tahun 2016} \\
\hline 1 & Dyah & Tepung Bumbu & Ngijo Karangploso \\
\hline 2 & Befinda & Catering & Ngijo Karangploso \\
\hline 3 & Ayu & Catering & Ngijo Karangploso \\
\hline 4 & Umi & Krupuk & Ngijo Karangploso \\
\hline 5 & Andik & Knipik Pisang & Ngijo Karangploso \\
\hline 6 & Hen Puji & Untuk Yuyu & Ngijo Karangploso \\
\hline 7 & Lilis & Jamur Krispi & Ngijo Karangploso \\
\hline 8 & Narti & Jamu Gendong & Ngijo Karangploso \\
\hline 9 & Enyanti & Gorengan & Ngijo Karangploso \\
\hline 10 & Humam Haris & $\begin{array}{l}\text { Jipang dari Ketan, } \\
\text { Blinjo, Jagung pipih }\end{array}$ & Blitar \\
\hline 11 & Yayuk & Brownis & Kalirejo Lawang \\
\hline 12 & Endang & Kue Kering & Kalirejo Lawang \\
\hline 13 & Nganti Piwelas & Kue Kering & Kalirejo Lawang \\
\hline 14 & Bekti Wiba & Kue basah/kue kering & Kalirejo Lawang \\
\hline 15 & Topo & Gorengan & Kalirejo Lawang \\
\hline 16 & Diana & Keripik & Kalirejo Lawang \\
\hline 17 & Ema N & Bakso & Kalirejo Lawang \\
\hline 18 & Sutini & Bandeng Presto & Kalirejo Lawang \\
\hline 19 & Warsini & Ayam lalapan & Kalirejo Lawang \\
\hline 20 & Emi Lutfiati & Permen coklat & Kalirejo Lawang \\
\hline 21 & Yusuf & Jamu & Kalirejo Lawang \\
\hline 22 & Dominggus & Minuman & Kalirejo Lawang \\
\hline 23 & Kamto & Bakpao & Ketindan Lawang \\
\hline 24 & Supiati & Jamu instan & Ketindan Lawang \\
\hline 25 & Man & Bakso & Ketindan Lawang \\
\hline
\end{tabular}

\begin{tabular}{|c|c|c|c|c|c|c|}
\hline Keterangan & \multicolumn{6}{|c|}{$\operatorname{Tahn} 2015$} \\
\hline & Sif & Agst & Sept & $\mathrm{CH}$ & Sop: & Des \\
\hline Pendapatan Jasa & 265.000 & 43560 & 255000 & 105.500 & 305000 & 5365.000 \\
\hline Penjualan & 12.755 .000 & 2351500 & 130960000 & 4932000 & 15300.000 & $7+300.200$ \\
\hline Harga Pkok Peng & $12+20.000$ & 2197000 & 12764000 & 4775200 & 15355000 & 66355.000 \\
\hline Laba & 600.000 & 198.000 & 587000 & 312300 & 750.000 & 13250.000 \\
\hline
\end{tabular}

Kondisi keuangan 6 bulan terakhir tahun 2015 sebagai berikut :

$\begin{array}{llr}\text { Kas } & : R p & 26.437 .663,- \\ \text { Persediaan barang dagangan } & : R p & 36.566 .159,- \\ \text { Piutang usaha } & : R p & 48.852 .134,- \\ \text { Pendapatan Jasa } & : R p & 6.279 .000,- \\ \text { Penjualan } & : R p & 123.284 .500,- \\ \text { Laba } & : R p & 15.597 .300,-\end{array}$

Jumlah kas, persediaan serta piutang semester ke 1 tahun 2016 sbb:

\begin{tabular}{|c|c|c|c|c|c|c|}
\hline \multirow[t]{2}{*}{ Keterangan } & \multicolumn{6}{|c|}{ Tahme 201} \\
\hline & sdilan & sdPokr & 5dMar & sdAgr & sdMé & sd.hri \\
\hline Kas & 25.504 .663 & 27539.663 & 28.829 .665 & 15919.163 & 8.165 .663 & $13.590350-$ \\
\hline Persedaan & 33921.459 & 30.647 .459 & 32344959 & 45015.459 & 15.472359 & 22270.560 - \\
\hline Fitang usaha & 52.844 .134 & 54.466 .634 & 51.846 .634 & 52264.134 & 24.298 .134 & $37.997350-$ \\
\hline
\end{tabular}

Jumlah Pendapatan Jasa, Penjualan barang dagangan dan laba semester ke 1 tahun 2016 sbb:

\begin{tabular}{|c|c|c|c|c|c|c|}
\hline Ketermgan & \multicolumn{6}{|c|}{ Thum 2016} \\
\hline & $\operatorname{Jan}$ & Pabr & Mar & Afye & Mei & fin \\
\hline Pendapatan Jasa & 85.000 & $10250 \%$ & 18.750 & 40000 & 285000 & 393360 - \\
\hline Perijualan & 6.487000 & 6382500 & 6948.750 & 3250000 & 13553000 & 7680920 - \\
\hline Bang Prok Pang & 6157.300 & 6101508 & 67000009 & 3.112500 & 132400000 & 27340210 - \\
\hline Laba & 414300 & 383500 & 367300 & 177500 & 628.000 & $734.070-$ \\
\hline
\end{tabular}

Kondisi keuangan 6 bulan pertama tahun 2016 s/d Juni sebagai berikut :

$\begin{array}{llr}\text { Kas } & : \mathrm{Rp} & 13.590 .330,- \\ \text { Persediaan barang dagangan } & : \mathrm{Rp} & 22.270 .560,- \\ \text { Piutang usaha } & : \mathrm{Rp} & 37.997350,- \\ \text { Pendapatan Jasa } & : \mathrm{Rp} & 1.024 .610,- \\ \text { Penjualan } & : \mathrm{Rp} & 64.332 .170,- \\ \text { Laba } & : \mathrm{Rp} & 2.704 .870,-\end{array}$

2. Aktivitas Usaha Sentra Kulakan Binaan (Kaliarto) desa Kalirejo Kec Lawang Kab Malang tahun

$\begin{array}{llr}\text { Kas } & : \mathrm{Rp} & 9.250 .163,- \\ \text { Persediaan barang dagangan } & : \mathrm{Rp} & 15.770 .359,- \\ \text { Piutang usaha } & : \mathrm{Rp} & 23.638 .134,- \\ \text { Pendapatan Jasa } & : \mathrm{Rp} & 1.452 .900,- \\ \text { Penjualan } & : \mathrm{Rp} & 72.801 .600,- \\ \text { Laba } & : \mathrm{Rp} & 3.623 .250,-\end{array}$

Jumlah kas, persediaan serta piutang semester ke 2 tahun $2015 \mathrm{sbb}$ :

\begin{tabular}{|c|c|c|c|c|c|c|}
\hline \multirow{2}{*}{ Keterangan } & \multicolumn{6}{|c|}{ Tahm 2015} \\
\hline & sdifif & sdAgust & sd Seypt & sdokt & $s d \mathrm{dsp}$ & sidDes \\
\hline $\mathrm{K}_{35}$ & 12094.163 & 11.659 .163 & 9.690 .163 & 9927.663 & 10.682 .663 & 26.437 .663 \\
\hline Persetiaan & 13.245 .359 & 15.326359 & 15201.359 & 15311159 & 15938.659 & 36.566 .159 \\
\hline Futang watha & 23919.134 & 22.41 .134 & 25.152 .134 & 25.117 .134 & 24.484 .634 & 48.852134 \\
\hline
\end{tabular}

Jumlah Pendapatan Jasa, Penjualan barang dagangan dan laba semester ke 2 tahun 2015 sbb:

\begin{tabular}{|c|c|c|c|}
\hline Bulan & Belanja & Penjualan & Laba \\
\hline \multicolumn{4}{|c|}{ Tahun 2015} \\
\hline Juli & Rp 5.265.340,- & $\operatorname{Rp} 2.242 .900,-$ & Rp 153.350,- \\
\hline Agustus & $\operatorname{Rp} 3.449 .810,-$ & Rp 1.490.080,- & Rp 144.920, \\
\hline September & $\operatorname{Rp} 4.270 .700,-$ & Rp $811.000,-$ & $\operatorname{Rp} 132.600$, \\
\hline Oktober & Rp 1.119.500,- & Rp 2.556.000,- & $\operatorname{Rp} 339.900$. \\
\hline Nopember & Rp $794.650,-$ & Rp 1.591.450,- & $\operatorname{Rp} 168.800$ \\
\hline Desember & Rp 3.833.000,- & Rp 2.575.000,- & $\operatorname{Rp} 590.000$, \\
\hline \multicolumn{4}{|l|}{ Tahun 2016} \\
\hline Januari & $\operatorname{Rp} 2.219 .500,-$ & Rp 1.461.600,- & Rp 161.600, \\
\hline Pebruari & Rp 1.861.000,- & Rp 3.030.200,- & $\operatorname{Rp} 285.100$ \\
\hline Maret & $\operatorname{Rp} 2.300 .000,-$ & \begin{tabular}{|l|}
$\operatorname{Rp} 1.185 .000,-$ \\
\end{tabular} & Rp 165.000, \\
\hline April & $\operatorname{Rp} 2.750 .000,-$ & Rp 3.025.000,- & $\operatorname{Rp} 275.000$, \\
\hline Mei & $\operatorname{Rp} 2.886 .150,-$ & $\operatorname{Rp} 966.700,-$ & Rp 142.800, \\
\hline Juni & $\operatorname{Rp} 2.875 .200$ & Rp 2.076.000,- & $\operatorname{Rp} 325.000$. \\
\hline Juli & $\operatorname{Rp} 4.879 .240$ & $\operatorname{Rp} 3.084 .000$ & $\operatorname{Rp} 673.500$ \\
\hline
\end{tabular}


3. Pertumbuhan Penjualan Sentra Kulakan Binaan (Ketindan Sari) desa Ketindan Kec Lawang Kab Malang

\begin{tabular}{|c|c|c|c|}
\hline Bulan & Belanja & Penjualan & Laba \\
\hline \multicolumn{4}{|l|}{ Tahun 2015} \\
\hline Juli & Rp 5.434.800,- & Rp 3.487.400,- & $\operatorname{Rp} 289.500,-$ \\
\hline Agustus & Rp 3.916.000,- & Rp 3.600.550,- & Rp 321.900,- \\
\hline September & Rp 5.060.600,- & Rp 4.120.990,- & $\operatorname{Rp} 222.780,-$ \\
\hline Oktober & Rp 4.720.500,- & Rp 2.980.540,- & Rp 198.990,- \\
\hline Nopember & Rp 2.738.500,- & Rp 2.679.200,- & $\operatorname{Rp} 207.680,-$ \\
\hline Desember & Rp 2.263.800,- & Rp 1.989.000,- & $\operatorname{Rp} 226.500,-$ \\
\hline \multicolumn{4}{|l|}{ Tahun 2016} \\
\hline Januari & Rp 3.537.500,- & Rp 3.334.630,- & Rp 302.650,- \\
\hline Pebruari & Rp 3.042.690,- & Rp 2.788.300,- & $\operatorname{Rp} 265.780,-$ \\
\hline Maret & Rp 661.300,- & Rp 1.089.900,- & $\operatorname{Rp} 289.660,-$ \\
\hline April & Rp 3.225.000,- & $\operatorname{Rp} 2.675 .920,-$ & $\operatorname{Rp} 254.300,-$ \\
\hline Mei & Rp $912.000,-$ & Rp 1.090.340,- & $\operatorname{Rp} 263.450,-$ \\
\hline Juni & Rp1.811.500,- & Rp 1.098.300,- & Rp 301.240,- \\
\hline Juli & $\mathrm{Rp} 1.231 .190,-$ & Rp 1.333900,- & $\operatorname{Rp} 285.500,-$ \\
\hline
\end{tabular}

Banyak UMKM bergairah kembali, UMKM yang telah mati suri kembali bisa beroperasi, sehingga kehidupan keluarga prasejahtera (pelaku UMKM) baik secara ekonomi maupun sosial semakin membaik.

Peredaran uang diwilayah sentra kulakan berada semakin banyak. Dengan bergairahnya kegiatan ekonomi UMKM dan sentra kulakan tentunya menambah kapasitas uang beredar diwilayah tersebut.

Pendapatan UMKM dan sentra kulakan meningkat karena semakin produktif UMKM juga akan berakibat semakin banyak pasokan barang yang harus disediakan sentra kulakan dan efeknya adalah semakin banyak pendapatan sentra kulakan dari hasil menjual barang kepada UMKM dan masyarakat.

Kesejahteraan masyarakat bawah meningkat. Terpenuhinya kebutuhan permodalan bagi UMKM untuk mengiatkan kembali usaha, akan berakibat pada peningkatan pendapatan UMKM sehingga akan berefek meningkatkan kesejahteraan mereka, karena pendapatan dari usahanya semakin meningkat.

\section{KESIMPULAN}

\section{Kesimpulan}

Sentra Kulakan yang dibentuk tim di 3 desa binaan sangat besar artinya bagi masyarakat sekitar terutama bagi pengelola UMKM. Adannya sentra kulakan telah mampu menggairahkan perekonomian masyarakat terutama UMKM binaan sentra kulakan, hal ini bisa dilihat semakin banyak bermunculan kembali UMKM yang selama ini hidup segan mati tak mau. Adanya permodalan usaha dalam bentuk bahan baku usaha yang disupply sentra kulakan menyebabkan UMKM yang semula sudah kurang produktif menjadi bergairah lagi, hal ini juga ditunjang adanya bantuan peralatan yang dibutuhkan untuk produksi dan beberapa pelatihan ketrampilan.

\section{Saran}

a. Hendaknya pemerintah Kabupaten Malang selain memberikan pelatihan juga memberikan peralatan yang dibutuhkan UMKM sesuai dengan keperluannya.

b. Bagi Perguruan Tinggi hendaknya lebih peka terhadap kehidupan UMKM yang ada di daerah pedesaan dengan lebih banyak mengadakan pembinaan kepada UMKM di desa

\section{DAFTAR PUSTAKA}

Peraturan Daerah Kabupaten Malang, Nomor : 2 tahun 2011 Tentang Rencana Pembangunan Jangka Menengah Daerah (RPJMD) Kabupaten Malang Tahun 2010-2015

Teropong, Buletin Balitbang Provinsi Jawa Timur, Edisi 64 Juli-Agustus 2012, ISSN 1412-8829

http://www.lensaindonesia.com/2012/10/12/menkopukm-resmikan-sentra-kulakan-posdaya-dipacitan.html

http://www.gemari.or.id/cetakartikel.php?id=6051 Sentra Kulakan Posdaya Pacitan Wujud Pro Ekonomi Kerakyatan. 